\title{
Microbes are Friends or Foes? A Review
}

\author{
Hafiz Hussain Ali ${ }^{1}$, Ali Ahmad ${ }^{2, *}$, Ehsan Ullah ${ }^{2}$, Ahmad Kamal', Muhammad Yasir Nawaz ${ }^{3}$, Aown Abbas ${ }^{4}$, \\ Saman Khalid ${ }^{5}$, Ahsan Raza Khan ${ }^{4}$ \\ ${ }^{1}$ Institute of Soil and Environmental Sciences, University of Agriculture Faisalabad, Faisalabad, 38000, Pakistan. \\ ${ }^{2}$ Department of Agronomy, University of Agriculture Faisalabad, Faisalabad, 38000, Pakistan. \\ ${ }^{3}$ Department of Pathology, Faculty of Veterinary Science, University of Agriculture Faisalabad, Faisalabad, 38000, Pakistan. \\ ${ }^{4}$ Department of Soil \& Climate Sciences, University of Haripur, Khyber Pakhtunkhwa, Pakistan. \\ ${ }^{5}$ Department of Forestry Range and Wildlife Management, The Islamia University of Bahawalpur, Bahawalpur, Punjab, Pakistan.
}

How to cite this paper: Hafiz Hussain Ali, Ali Ahmad, Ehsan Ullah, Ahmad Kamal, Muhammad Yasir Nawaz, Aown Abbas, Saman Khalid, Ahsan Raza Khan. (2022). Microbes are Friends or Foes? A Review. Advance in Biological Research, 3(1), 1-7. DOI: 10.26855/abr.2022.01.001

Received: December 1, 2021

Accepted: December 25, 2021

Published: January 12, 2022

Corresponding author: Ali Ahmad, Department of Agronomy, University of Agriculture Faisalabad, Faisalabad, 38000, Pakistan.

Email: aliahmadsial2643@gmail.com

\begin{abstract}
Just of surviving as solitary planktonic cells, microorganisms such as bacteria, archaea, fungus, microalgae, and viruses establish complex interaction networks within the ecosystem. Interactions between microorganisms can occur between members of the same species, between members of different species, or even between members of other genera, families, or domains. These interactions take place following environmental sensing and the conversion of those signals to molecular and genetic information, which involves a variety of processes and molecule types. Microbes' essential tactics for colonizing and establishing in a range of habitats are revealed in comprehensive investigations of microbial interactions. Understanding the processes behind microbial interactions is critical to comprehending microorganisms' ecological influence and the emergence of dysbioses. It might be the key to utilizing tactics and specialized agents to combat a variety of issues, including chronic and infectious illnesses, malnutrition, pollution, and sustainability.
\end{abstract}

\section{Keywords}

Archaea, Bacteria, Fungus, Microalgae, Microbial interactions, Viruses

\section{Introduction}

We can see many organisms but some living organisms are very small. We cannot see, hear or feel these living organisms but they are always with us, so microscope is compulsory to see them. These organisms are called microbes or microorganisms. Without microorganisms, we cannot survive. For example hookworm (Figure 1) parasite lives in the human body.

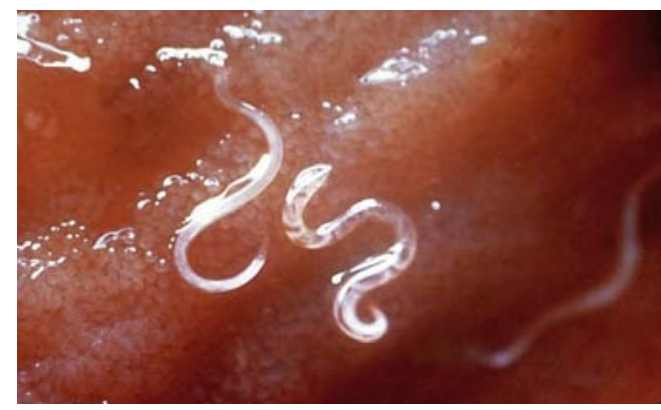

Figure 1. Hook worm [2]. 
These organisms are single-celled or unicellular. Microorganisms exist almost everywhere in the nature. Microorganisms live around and inside us. They help clean up our environment. They also help to produce different foods. Many different benefits of microorganisms but they also cause harmful effect. For example, we see growing of fungus on bread when bread left for some of days due to moisture content in the bread. This is most loving conditions for growing of microbes [1].

\section{Classification of Microorganism}

Four important and major groups of microorganisms are given below:
a) Bacteria
b) Fungi
c) Algae
d) Protozoa

Largest human cells are considered equal to the diameter of a human hair. Cells of bacteria are 1 hundredth the human cell size and viruses are much smaller. Viruses are different from microbes but microscopic. Viruses are different from bacteria in the aspects of reproduction because viruses reproduce only in host's cell. These hosts are animals, plants and bacteria. Virus has molecule of nucleic acid and protein coating [2].

\subsection{Bacteria}

Mostly bacteria (Figure 2) are harmless, but the pathogenic bacteria cause the disease. Different bacteria shapes help us to place bacteria in different family groups:

- $\quad$ Bacilli with and without flagella

- Streptococci

- $\quad$ Staphylococci

- Diplococci

- Spirochete

- Club rod

- Filamentous

- Streptobacilli

Bacteria have different shapes e.g. some bacteria look like balls, rods and spirals. For energy and growth bacteria need to eat (ingest) like all other living organisms. Bacteria ingest sugars \& starches that are found on all the organic matter [3].

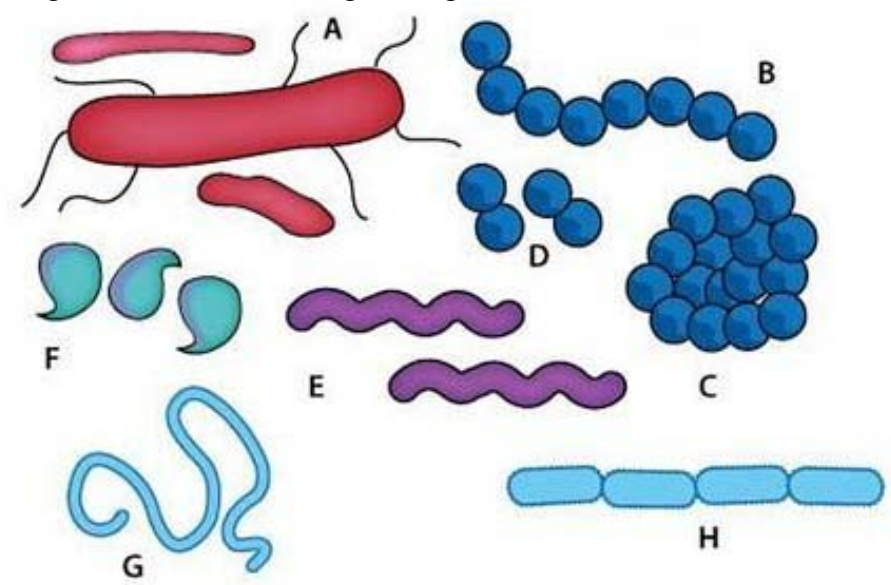

Figure 2. Bacteria [2].

\subsection{Disease causing bacteria}

Many disease causing bacteria that are surprisingly present on or in our bodies. Genus Streptococcus is the most important group of commensal bacteria. Numerous infections including the pneumonia cause by important group of commensal bacteria. Strain of Streptococcus pyogenes cause skin infection [4]. 
Almost one-tenth of the total population carrying streptococcus pyogenes bacterium around in their noses \& throats and usually it does no harm at all, Streptococcus pyogenes carries the proteins on its cell surface that resemble to the human proteins, that's why immune system cannot destroy the Streptococcus Pyogenes. Due to human proteins resemblance immune system think it is the part of the human body that's why immune system preventing and not destroy. If out of balance growth of commensal species with the rest natural microbial population can cause infection in the human body. Activity and size of population of each species of commensal kept in check by competition with other commensals, if the disrupted balance occur then some commensal or foreign microbes may be a chance to multiply and becomes more active.

In our gut many anaerobic bacteria naturally found may also cause disease. Genus Clostridium bacteria are commonly found in the soil and responsible for disease range in people.

Between one another genetic information can transfer by microbes and resistance of antibiotic among the population of microbes is spread. The route is the foundation of MRSA. In sewage plants beneficial microbes play an important role in the breakdown of human waste [5].

\subsection{Viruses}

Microorganisms that are so basic and even not classified as living are viruses (Figure 3). Viruses are only the genetic material (DNA or RNA) wrapped up inside a strong 'coat' made of protein. Different shapes of viruses e.g. rods, spheres and many-sided spheres. Pathogenic viruses are very dangerous but some are good [6].

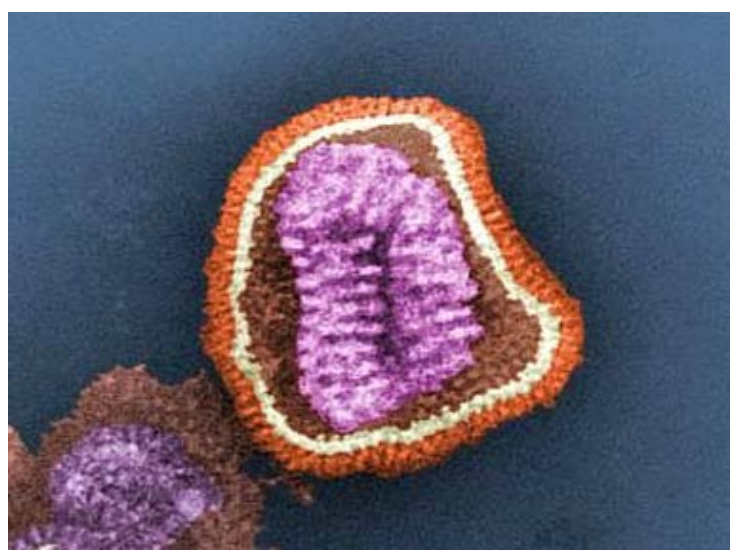

Figure 3. Virus [2].

\subsection{Parasites}

In a very unequal or disturbed relationship, parasites live inside or on its host organism. Parasite takes all the food does not give anything back to its host. Parasites can be live in or on our bodies (like lice) and cause different diseases. Parasitic worms including the hookworms and protozoa (Figure 4) live in the human and animal's bodies and make us sick [6].

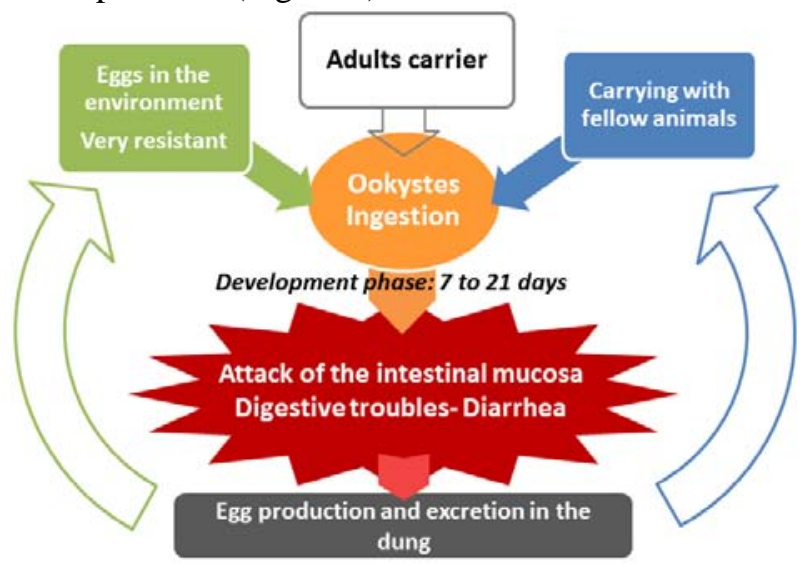

Figure 4. The prevention of digestive troubles caused by protozoa in young ruminants [7]. 


\section{Friend and foe}

Protozoa, algae, fungi, bacteria and viruses (Figure 5) are the important microorganisms present in and on our body. Most beneficial microorganisms, for example, in large intestine there are microorganisms that synthesise vitamins and allow them to absorb into the bloodstream. However, very small quantity of microorganisms is pathogens (disease-causing agents). These pathogens usually called germs or bugs.

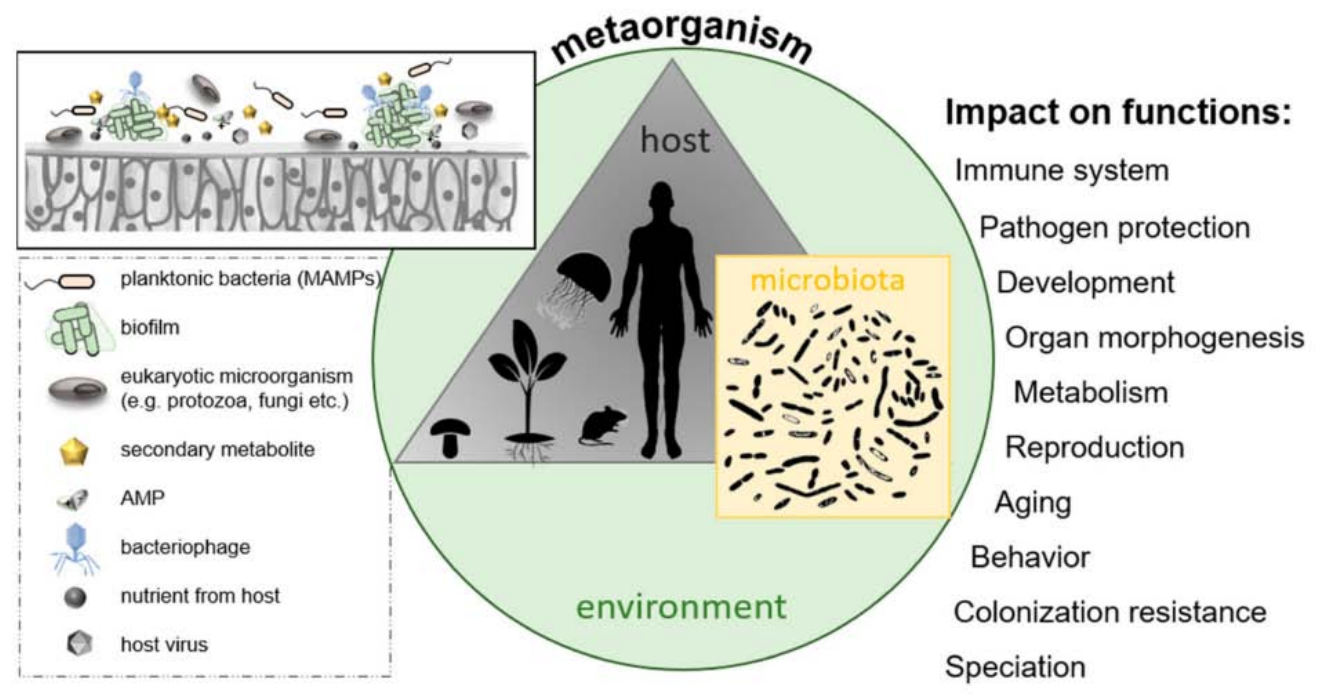

Figure 5. The metaorganism concept [8].

\subsection{Few uses of beneficial microorganisms are given below:}

- In the baking industry, huge use to make bread, cakes, etc.

- Uses of microorganism in the production of milk products, i.e., curd formation from the milk by using the Lactobacillus bacteria.

- $\quad$ For making of organic acids microorganisms are used (Figure 6).

- Microorganisms are used in the production of vitamins, i.e., Vitamin B complex, acetobacter species produce the vitamin C (Ascorbic acid).

- Soil fertility increase due to microorganisms.

- $\quad$ Sewage treatment with the help of microorganisms.

- Microorganisms used in pest control [9].

\section{Harmful Microorganisms}

Pathogens cause diseases in the living organisms. In our bodies, pathogens can enter through air, water and food. Directly or indirectly disease transmitted through infected person are known as communicable diseases, for example, common cold, tuberculosis, etc. Foods spoil because microorganisms grow on it. That's why preservatives are used to prevent food from spoilage.

\subsection{Diseases Caused By Microorganisms}

Some diseases due to microbes are given below:

1) Bacteria cause many diseases like tuberculosis, typhoid, cholera, plague, meningitis, tetanus, lyme disease etc.

2) Fungi cause many diseases like ringworm, athlete's foot, candidiasis, tinea versicolor, onychomycosis etc.

3) Dysentery, malaria, chagas disease, sleeping sickness, intestinal protozoan disease caused by protozoa.

4) Virus cause many diseases like flu and common cold, warts, polio, herpes and cold sores, chickenpox, smallpox, ebola etc. (Figure 7). 


\subsection{Diseases Caused by Microorganisms in Animals}

Bacillus anthracis cause anthrax diseases and virus cause foot and mouth disease in the animals.

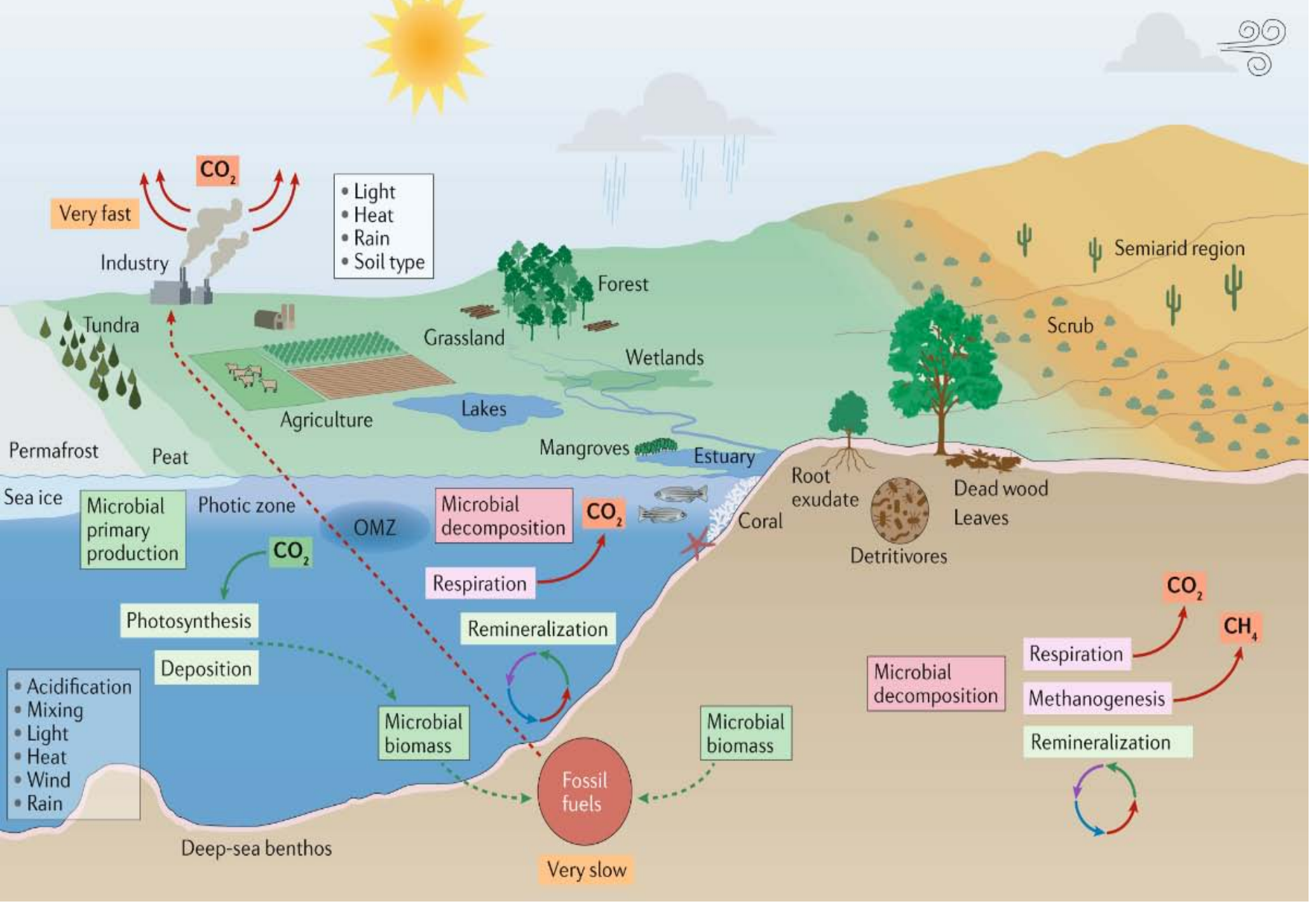

Figure 6. Microorganisms and climate change in marine and terrestrial biomes [10].

\subsection{Diseases Caused by Microorganisms in Plants}

Bacteria cause citrus canker, fungi cause wheat rust and virus cause yellow vein mosaic of okra.

\subsection{Microorganisms spoil the food}

1) Food quality damage that makes it unsuitable for human consumption.

2) Moulds, bacteria and yeast are the main source of food spoilage.

3) Activity of water reduced and food spoil due to moulds. For example dry cereals and products of cereals.

4) Important food constituents decompose due to certain enzymes produced by microbes.

5) On the other hand, spoilage of food with increased water activity due to bacteria. For example milk products [11].

\section{Few interesting facts about Microbes}

a) Microbes can be fatal.

b) Change of mood due to presence of microbes in our gut.

c) As compared to damp hands dry hands have fewer bacteria.

d) Mycoplasma is the smallest known bacteria. 
e) 50 percent of the oxygen comes from microbes.

f) More than 1400 bacteria only in the belly button.

g) In a person's mouth than a billion microbes are present (Figure 8).

h) $1.82 \mathrm{kgs}$ body's weight of human constitutes the collective weight of microbes in human body [13].

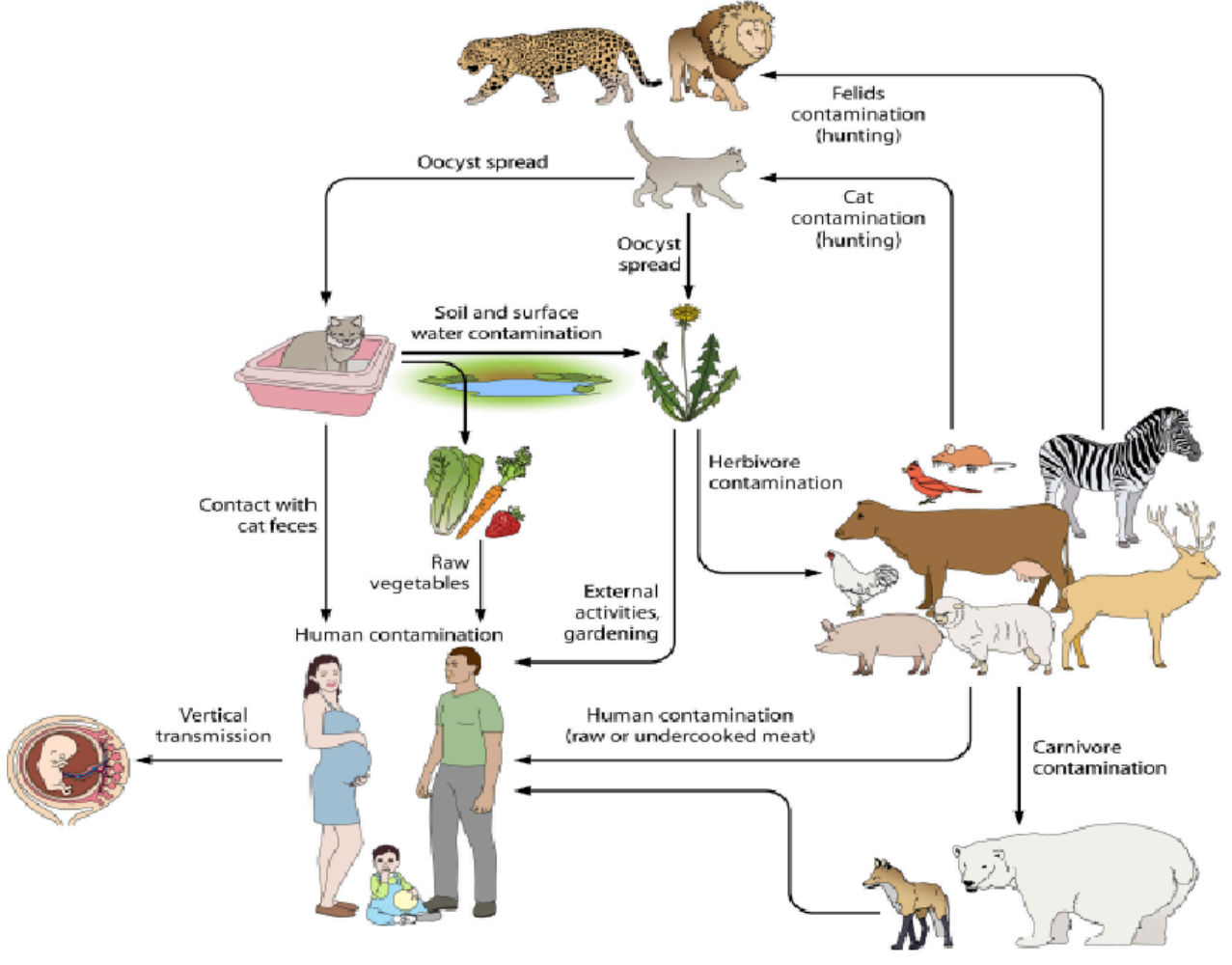

Figure 7. Sources of T. gondii infection in humans [12].

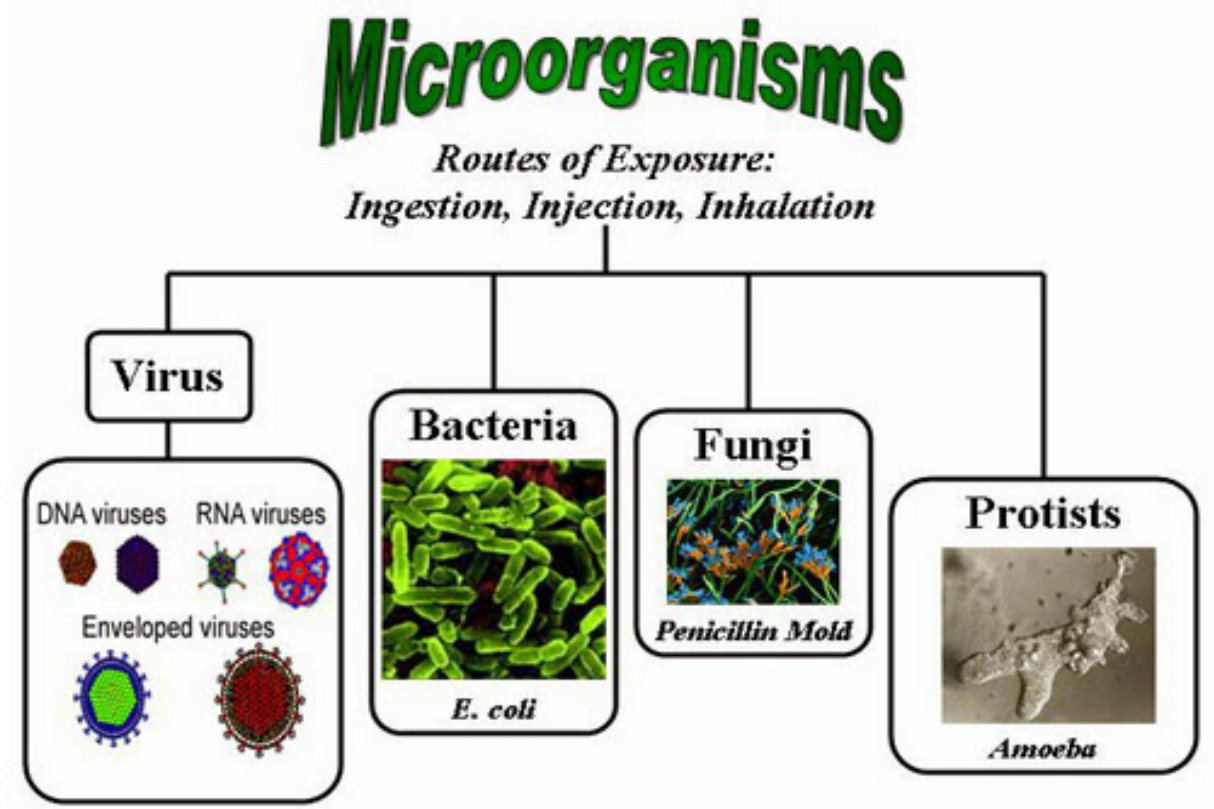

Figure 8. Fun facts about micro-organisms [14]. 


\section{References}

[1] Https://byjus.com/biology/microorganisms-friend-and-foe/.

[2] Https://www.sciencelearn.org.nz/resources/176-microorganisms-friend-or-foe.

[3] Https://www.open.edu/openlearn/nature-environment/microbes-friend-or-foe/content-section-1.

[4] Sommer, F. and Bäckhed, F. (2013). The gut microbiotamasters of host development and physiology. Nature Reviews Microbiology, 11(4), 227-238.

[5] Cole, L. A. (2003). The Anthrax Letters. A Bioterrorism Expert Investigates the Attack that Shocked America. New York, NY: DC: Skyhorse Publishing.

[6] Vos, T., Allen, C., Arora, M., Barber, R. M., Bhutta, Z. A., Brown, A.,... and Coggeshall, M. (2016). Global, regional, and national incidence, prevalence, and years lived with disability for 310 diseases and injuries, 1990-2015: a systematic analysis for the Global Burden of Disease Study 2015. The Lancet, 388(10053), 1545.

[7] https://www.natual-techna.com/en/parasitic-sanitary/ruminant/protozoa-calves.

[8] Weiland-Bräue, N. (2021). Friends or Foes-Microbial Interactions in Nature. Biology. 10 : 496. https://doi.org/10.3390/biology10060496.

[9] Li, Z., Yang, S., Lin, H., Huang, J., Watkins, P. A., Moser, A. B., ... and Diehl, A. M. (2003). Probiotics and antibodies to TNF inhibit inflammatory activity and improve nonalcoholic fatty liver disease. Hepatology, 37(2): 343-350.

[10] Cavicchioli, R., Ripple, W. J., Timmis, K.N., et al. (2019). Scientists’ warning to humanity: microorganisms and climate change.

[11] Rawat, S. (2015). Food Spoilage: Microorganisms and their prevention. Asian Journal of Plant Science and Research, 5(4): 47-56.

[12] Singh, S. R., Krishnamurthy, N. B., and Mathew, B. B. (2014). A Review on Recent Diseases Caused by Microbes.

[13] Yamamoto, N., Akino, A., and Takano, T. (1994). Antihypertensive Effect of the Peptides Derived from Casein by an Extracellular Proteinase from Lactobacillus helveticus CP790. Journal of Dairy Science, 77(4): 917-922.

[14] Http://knowledge-sastha.blogspot.com/2013/11/fun-facts-about-micro-organisms.html. 